
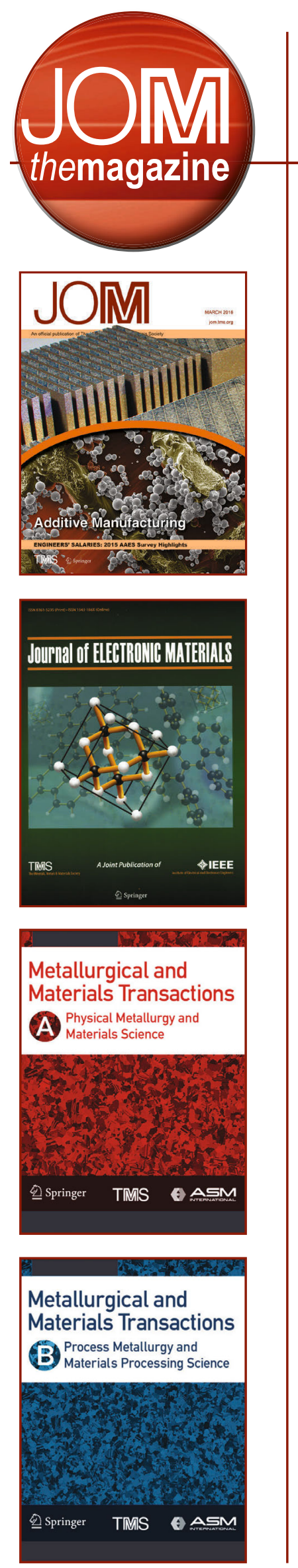

1462

\title{
Impact Factors of TMS Journals Continue Upward Trend
}

\section{TMS content update}

Look for news and updates on TMS publications and online resources, as well as opportunities for editors and authors, in this regular JOM feature.

The Impact Factors (IF) for TMS's four long-established journals increased with the recent release of the 2016 Journal Citation Reports (Clarivate Analytics, 2017). IF is based on the number of citations of a journal's materials divided by the number of citable materials published by that journal.

JOM, Journal of Electronic Materials, and Metallurgical and Materials Transactions $A$ and $B$ all experienced IF increases. What follows are the 2016 IF numbers for TMS journals (with the 2015 IF in parentheses):

- JOM: 1.860 (1.798)

- Journal of Electronic Materials: 1.579 (1.491)

- Metallurgical and Materials Transactions A: 1.874 (1.749)

- Metallurgical and Materials Transactions B: 1.642 (1.474)

While IF can vary from year to year for a variety of reasons, TMS journals have generally tracked in a positive direction (Figure 1). Authors often refer to the IF of a journal for guidance when seeking to maximize exposure of their work. A number of considerations, however, can "impact the Impact Factor."

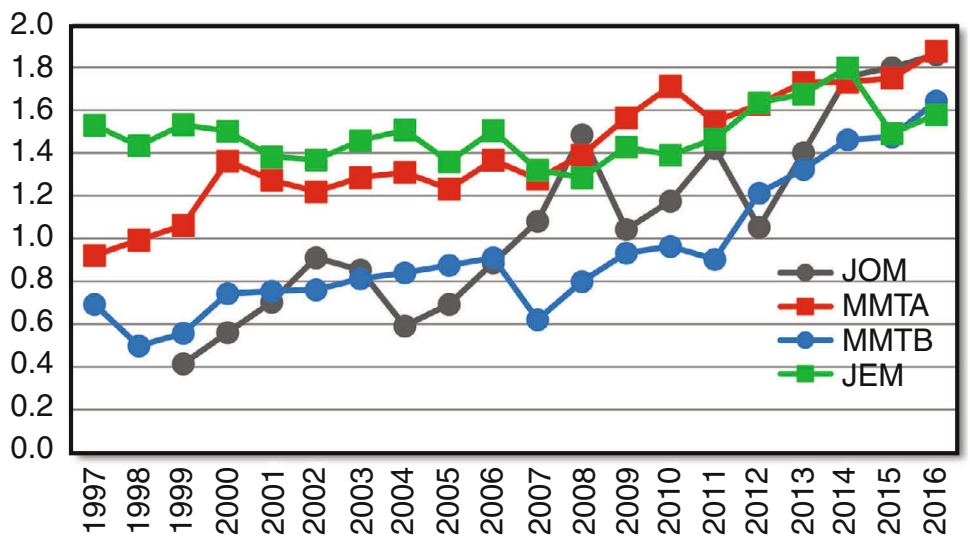

Figure 1. The Impact Factor scores of TMS's established journals have generally exhibited an upward trend over the years.
Review articles, for instance, typically generate more citations, while an increase or decrease in the number of articles published during the reporting timeframe can also influence the citation average.

Still, notes James J. Robinson, TMS Executive Director, the IF is a valuable tool for monitoring the ongoing progress and development of a journal. "Contributing to the body of knowledge through high-quality journal publication is fundamental to the Society's value to the professional community," he said. "While Impact Factor can fluctuate over time, the steady, upward trend for TMS journals is a strong indicator of the influence and importance of these periodicals."

"This latest news also serves as a testament to the dedication and commitment of the editors, peer reviewers, and other volunteers, as well as staff who work so hard to ensure that what we publish presents some of the best work that the field has to offer," Robinson continued. "We celebrate their efforts when we receive a positive Impact Factor report."

To access TMS's entire library of journals, visit the Journals section within the Publications tab on the TMS website at www.tms.org. Here, TMS members can read for free current and archived issues of not only TMS journals, but also 20 materials-related journals published by Springer. To begin reading, members should first $\log$ in to the TMS website and then select the journal they wish to read. 